\title{
Potentials and Limitations of Computer-Mediated Communication Theories for Online Incivility Research: A Focus on Bystander Dynamics
}

\author{
Yeweon Kim \\ University of California, Santa Barbara \\ yeweonkim@ucsb.edu
}

\begin{abstract}
This paper provides a comprehensive review of the five major theories of computer-mediated communication $(C M C)$ in order to explore how each theory can illuminate the processes and effects of contemporary online incivility phenomena on bystanders. These theories include: social presence theory, reduced social cues perspective, social identity model of deindividuation effects, social information processing theory, and hyperpersonal model of CMC. Of these five, this paper gives the most discussion to the first three theories that offer relatively more useful explanations of uncivil and antisocial behaviors in $C M C$, in terms of contributions of limited nonverbal social cues, and then explicates them with respect to the dynamics of online bystanders witnessing those problematic behaviors. This paper also examines, albeit relatively briefly, why the other theories are less useful but still have potentials for researching online bystanders. Further considerations needed to develop each theory and future research are discussed in the conclusion.
\end{abstract}

\section{Introduction}

Initial research on CMC was optimistic about its enhanced capabilities for "cool communication" [1], which could realize more efficient information exchange and equal participation by virtue of minimized interpersonal noise, compared to face-to-face (FTF) communication [2]. Before long, scholars increasingly discussed the limitations of CMC, noting its technologically induced anonymity and lack of nonverbal cues. Although some suggested that CMC facilitates moderate exchanges of socioemotional content [3], many concluded that it is devoid of the norms governing social interactions, which in turn triggers uninhibited and aggressive communication behavior [4]. Relatively recently, scholars have suggested that CMC establishes normative contexts that favor or disfavor such behavior and have weakened the dubious link between CMC and impersonal communication [5].

There are two general theoretical approaches summarizing this change of perspective on CMC. One approach (labeled as a cues-filtered-out approach) holds a technologically deterministic view, and is used by the social presence theory and reduced social cues perspective. The other approach holds a social-psychological oriented view, and is used by the social identity model of deindividuation effects (SIDE), social information processing theory (SIP), and hyperpersonal model of CMC. The former group of theories assumes that the specific features of digital communication technology in and of themselves are primarily responsible for any changes noted in CMC (vs. FTF) contexts. The latter group of theories stresses the interaction between technology and the user, focusing on how the characteristics of the communicator, their interactions with others, and contextual factors affect the perceived capacities of CMC systems. Thus, both approaches reflect competing theoretical paradigms about $\mathrm{CMC}$ and, in a broader sense, communication itself.

Although readers may find these five theories reviewed in other sources, this paper focuses on describing how each theory can explain the dark side of CMC. This paper particularly tries to assess their status and prospect as a tool for studying online incivility - a manner of aggressive and disruptive online behavior that can range from uninhibited and incensed discussion, to hateful and outrageous speech, as well as more severe forms of harassment, such as purposeful embarrassment and physical threats - that has become the "new normal" in today's CMC [6, 7]. In doing so, the focus is on the processes and effects of these antisocial behaviors towards observers, namely bystanders, who are expected to serve a role of either intervening against or reinforcing the problem. Although the five theories are considered mature because of their explanatory power and empirical validity, there have been no explicit theoretical positions upon which systematic investigations of online incivility bystanders can be undertaken. Moreover, prior discussions in this area have heavily focused on those who are directly involved - that is, uncivil perpetrators (bullies) and their targets (victims) - and thus have paid less attention to those who are indirectly affected yet make up the majority of the public (i.e., bystander public or bystander audience) [8]. To fill this gap, this paper sheds light on exposurerelated concerns (cf. perpetration) for online incivility and thereby highlights the complexity of tackling this issue.

Evidence from the real world, however, suggests varying possibilities of using these $\mathrm{CMC}$ theories to explain the psychological and behavioral dynamics of online bystanders. For example, roughly one-quarter of Americans (28\%) say they have adjusted their online presence by changing privacy settings or quitting an online service, after witnessing harassment [9]. These results can 
be examined through the lens of social presence theory. It is also a well-known fact that people are less likely to act on behalf of a target in need if they are part of a large crowd [10] or they perceive themselves to be invisible, compared to when they can discern one another in a group setting [11]. The reason why such impersonal behavior is common when bystanders are given limited information about the focal incident and those involved is possibly explained by the reduced social cues perspective. A report on the damaged mental wellbeing of young people who witness an attack on a group they belong to [12] reveals the importance of group identification between targets and bystanders, which is relevant to the SIDE approach. Moreover, given that online incivility is more vague than traditional forms of violence/bullying, bystanders have difficulty interpreting the situation and how to behave [13]. This raises the question of whether online bystanders have sufficient time and opportunities to gain the information needed to reduce uncertainty about the situation, equivalent to those that offline bystanders have. The SIP theory can guide such inquiry. Meanwhile, the fact that sixty-nine percent of Americans blame the Internet and social media for escalating the level of incivility in their country [14] suggests the potential amplifying role of $\mathrm{CMC}$ (vs. FTF) features on this problem, which can be studied using the hyperpersonal model of CMC.

Taking all available evidence into account, this paper comprehensively reviews the applicability of each CMC theory for research of bystanders witnessing online incivility that occurs in individual, group, and crowd levels. Although the specific dynamics of bystander behavior may vary based on the particular behavior witnessed (e.g., cyberbullying, flaming, hate speech), this paper assumes that any form of uncivil CMC behavior is comparable since they similarly violate what is considered normative in human communication. Given that bystanders react to attacks on not only individual targets but also social groups/values [15], the particularities of different forms of online incivility may not fundamentally alter the moral and psychological mechanisms underlying bystander behavior.

Although this paper does not test one specific theory against another, based on quantitative and systematic analyses, it contributes to the literature by revisiting the five $\mathrm{CMC}$ theories and assessing their further utility. Each section includes numerous research examples that can help us understand both the potentials and limitations each theory has when explaining the phenomenon in question.

\section{Social presence theory}

Social presence is defined as the subjective quality of a medium that determines the degree of salience of interactants and their interpersonal communication in that medium [16]. It relates to other social psychology concepts, such as intimacy [17] and immediacy [18], which indicate a function of proximity and psychological distance between interactants, and often refers to "the degree to which a person is perceived as a real person in mediated communication" [19, p. 10]. Researchers assume that decreased social presence in $\mathrm{CMC}$ can create more distance between communicators and lead them to perceive each other as "semi-mechanical objects which can be ignored, insulted, exploited, or hurt with relative impunity" [20, p. 972]. People may regard less than desirable behavior as acceptable when they consider others to be more machine-like, rather than real social beings [21].

There has been general agreement that negative communicative behaviors (e.g., flaming, trolling, verbal aggression) occur with the diminished social presence conveyed in online environments. Due to weak reminders of the presence and proximity of conversation partners, people tend to focus on themselves more strongly than their audience [22], and, in turn, their deviant opinion and behavior could persist under low pressure to conform to social norms [23]. Supporting this, a classic study on Usenet, an early Internet newsgroup system, found that a large proportion of its users breached conventional communication etiquette when they forgot they were interacting with others and were not afraid of their verbal aggression being questioned [24]. Since then, researchers have examined the role of social presence in online disinhibition, which causes problematic use of social media [25] and its more toxic forms, such as expressions of hatred and use of violence/pornography sites [26].

Research further suggests that the lack of social presence online may cause a focal incident to be misinterpreted by perpetrators and targets. For example, less prompt feedback about the incident makes it hard for the perpetrator to accurately assess the target's distress and, thus, they feel less empathic [27]. Targets themselves may also have distorted perceptions depending on the degree of social presence. They may consider their victimization less severe than traditional violence/bullying when it occurs in an online setting with low social presence (e.g., email) [28]. Conversely, targets may feel more severely impacted in a high social presence context (e.g., picture/video clip) [29].

The focus of research on social presence and antisocial $\mathrm{CMC}$ has been often directed towards the stances of perpetrators and targets. Less attention has been given to bystanders who are possibly affected by their experience of witnessing the same incident. These people observe interactions not only between the perpetrator and target but also between other bystanders, in order to interpret the given situation and determine their response. In this process, the lack of social presence online can mislead bystanders' perceptions and result in inappropriate behaviors that may hamper the resolution of the situation. The bystander apathy effect (the idea that third-party witnesses of a critical incident have an opportunity to intervene but often do not do so when they are part of a group; [30]) suggests a more important implication of social presence for bystanders - a social inhibition effect 
on intervention. Latané and Darley [31] revealed: when bystanders could (a) see and be seen, (b) see but not be seen, (c) not see but be seen, or (d) neither see nor be seen by the other bystanders, those who thought they were alone intervened the most, followed by those in the noperceived-presence condition and then those in the halfpresence conditions; but bystanders in the full-presence condition intervened the least. Some social psychological processes may drive these results [32], such as pluralistic ignorance (i.e., the perceived presence of passive bystanders misleads the individual to interpret the situation as less critical than it actually is) and the diffusion of responsibility (i.e., the psychological costs of nonintervention are shared with others who are co-present).

Such an inhibitory role of the presence factor in bystander intervention hold for CMC as well. For example, it takes longer for an individual to receive help when the number of people present in an online group chat increases [33]. Also, people tend not to counterargue online uncivil speech when there is even the mere presence of prior reactions of any kind, compared to no reactions at all [34]. As such, if the perceived presence of others reduces a likelihood of intervention, this social inhibition effect may be pronounced in a high social presence context. But this reasoning is inconsistent with the basic premise of social presence theory, which equates increased social presence with increased positive outcomes. This theory assumes that individuals take on certain roles in social interactions - and believe others feel jointly responsible - to develop positive relations [16]. If so, a greater sense of others' existence can enhance a greater feeling of belonging and, in turn, create positive social outcomes [25]. However, this possibility conflicts with the well-known tendency of bystanders to become inactive when they believe others are present and observing their behavior.

In short, the existing social presence explanation in $\mathrm{CMC}$ research predicts that prosocial bystander behavior is less likely in a low social presence context, while the bystander apathy effect predicts the opposite. It thus seems paradoxical to juxtapose these competing views. However, in a broader sense, these two theories parallel each other because they are general theories that draw on the basic laws of human nature. Both cover multivariable processes that are common themes of social impact, which refers to "any of the great variety of changes in physiological states and subjective feelings, motives and emotions, cognitions and beliefs, values and behavior, that occur in an individual, human (or animal), as a result of the real, implied, or imagined presence or actions of other individuals" [35, p. 343]. In this sense, an integrated but flexible framework can be developed that encompasses the two theories' competing predictions by providing a more effective explanation of the relationship between social presence and bystander behavior in online contexts.

Technically speaking, CMC does not meet the originally proposed condition for the bystander apathy effect (i.e., the physical presence of others) although an imagined or presumed audience can be just as impactful as a real audience [36]. Hence, there may be a need for an alternative and more appropriate notion of "presence (of others)" when we approach online bystander dynamics. Social presence theory can offer useful insights in this respect, since it has addressed the "(mediated) presence" as a complex construct with several distinctive properties, including telepresence/spatial presence (a sense of being there in a virtual environment that creates illusion of place) [37] and copresence (a sense of being together in a virtual environment where individuals feel that others are accessible and available) [38]. Given that online people may have a unique presence that is defined not simply based on "here or not-here" but on a varying degree of self-controlled (in)visibility [39], we can speculate that online bystander behavior could be driven by the perceived copresence (cf. telepresence) of others.

It is notable that social presence is not a binary construct (present vs. absent) but defined on a continuum of varying levels. This conceptualization aligns with Goffman's understanding that copresence is grounded on the basic "sensory" awareness of others and spans a continuum from minimal to intense [40]. This is a good reflection of the uniqueness of $\mathrm{CMC}$, where people have an extended sense of being connected to others and in control of their (in)visibility level through technologies [39]. The concept of copresence also includes mutual awareness (i.e., an individual is aware of the other and the other is aware of the self) [38] and the awareness of others' reactions to the self [41]. It emphasizes psychological connections between interactants [42], beyond coexistence with one another, which may help explain the social psychological mechanisms underlying bystander behavior. In visually anonymous $\mathrm{CMC}$, bystanders may misleadingly believe there are more people (virtually) present than is true, like the metaphor of a light bulb in an infinity mirror [35]. If so, the copresence of only a few online others can more readily incur the bystander apathy effect.

Such inhibitory effects by the copresence factor may be more challenging with contemporary multimodal and interactive technologies, which are designed to magnify social presence experiences online. However, in the context of online incivility, increased social presence may not always be equated with good consequences; instead, less social presence (of the self and others) perceived by online bystanders may hamper the bystander apathy effect and encourage intervention by reducing their apprehension of evaluation by others [43]. Thus, how to adjust the level of social presence in CMC to ensure prosocial responses against online incivility is a tricky question that should be left to future researchers.

\section{Reduced social cues perspective}


The reduced social cues perspective holds that $\mathrm{CMC}$ is inherently disadvantaged compared to FTF communication because electronic signals convey fewer nonverbal social cues that help efficiently communicate a message's connotation and contextual information. Scholars of this perspective associate the technological aspects of CMC with its liberation potentials, which could increase equality of participation [44] and decrease status differentials [45], but also could yield risky group decisions [46]. These results are well illustrated in organizational CMC, where information exchanges through email (vs. FTF meeting) appear more often to be self-absorbed, uninhibited, and irresponsible [22]. This perspective suggests that when social cues, which signal the presence of others, are weak people might have less other-focused attention and perceive more privacy from surveillance. They might thus feel unrestrained in their communication and treat others in impulsive and hyper-responsive manners.

The belief underlying this perspective is that CMC leads people to a state of deindividuation - a state of losing their inner constraints and, as a result, showing impulsive behavior that is normally considered inappropriate [47]. Much of the debate surrounds this question: under what conditions does deindividuation cause aggressive behavior in CMC. Researchers have often concluded that the reduced social cues in $\mathrm{CMC}$ - due to technologicallyinduced anonymity and weak social feedback-decreased users' self-awareness, as well as their awareness of others [48]. But some researchers have challenged this view by questioning if antisocial and aggressive behavior is an inevitable outcome of $\mathrm{CMC}$ [5], suggesting that its occurrence is socially and culturally dependent on the way people perceive group norms in a deindividuated state [49].

The reduced social cues perspective highlights that CMC users may feel pressure to use any available means (even hostile language) to ensure they are being correctly understood in the absence of nonverbal cues and immediate feedback [50]. A study guided by this perspective reveals that people compose messages more aggressively when there are fewer social and visual cues present from others [26]. This tendency, coupled with the liberation potentials of anonymity, contributes to CMC's evolution as a highly free and open atmosphere for public discussion online [51]. However, this kind of CMC conversation often turns into vicious debates marked by incivility [52], with fewer social cues about the perpetrator than in FTF ones. Bystanders, as receivers of the perpetrator's message, may try to reduce their uncertainty of the incident, and, in doing so, their attention may be directed solely toward available verbal cues in the message.

Such a narrow focus on the perpetrator's message can act as an aggressive cue to elicit bystanders' own hostile perceptions through cognitive and affective priming, according to the general aggression model [53]. This happens even among bystanders who are free from dispositional characteristics relevant to aggressive attitudes.
Supporting this assumption, those exposed to uncivil user comments were found to experience hostile cognitions and emotions $[54,55]$ or report less open-mindedness about a discussed news issue [56]. Although such negative arousal may diminish after exposure, it can determine immediate behavior in response to the message. Exposure to uncivil discussions online could motivate bystanders to join the same discursive activities [57] through aggressive intentions [58] or defensive motivations [56]. If so, bystanders may be, correspondingly, more likely to act in ways that ease their distress by utilizing more assertive language and behavior, which seemingly results in externalizing the same problematic verbal behavior they witness. This may explain why being a bystander of online hate is positively related to being its perpetrator. This also hints at why this problem has become so prevalent [59].

Such a potential for bystanders to commit incivility can also be understood as a virtual form of behavioral synchrony (i.e., an instantaneous behavioral copying) and subsequent emotional convergence, namely emotional contagion [60]. Evidence that CMC users transfer their moods (both positive and negative) to others when there is a complete absence of nonverbal cues online [61] suggests that the amount of cues available is not necessarily a condition of emotional contagion. That is, the subtle adverse impact of online incivility exposure can occur to bystanders even in the cue-poor CMC setting. Exploring the possibility that bystanders themselves may engage in impersonal communication is another area that should be studied from the reduced social cues perspective.

More research is still needed on whether a lack of nonverbal cues serves as an impediment or a contributor to bystander intervention. As bystander research suggests, intervention is less likely when bystanders are in a highly ambiguous situation [62] or when they only hear about a situation without any visual/auditory cues [63]. The same can apply to anonymous CMC settings where a message alone may not be enough to construe whether the incident is intervention appropriate. But it is hard to conclude that more cue-availability will always increase the likelihood of intervention, as mentioned in the previous section. Another question to be raised is what kind of cues matter to bystanders. Given that the medium of presentation does not always alter the perceived severity of uncivil speech [64], the amount of visual cues about the incident itself may not significantly affect bystanders. Rather, cues that indicate who is online and active may be more significant by signaling the presence of an imagined audiencepossibly causing the implicit bystander (apathy) effect [65].

\section{Social identity model of deindividuation effects (SIDE)}

Along with a migration from the technologically deterministic view toward more consideration for social and group-level factors in $\mathrm{CMC}$, the social identity model 
of deindividuation effects (SIDE) has emerged as an alternative research paradigm [66]. This model still shares the basic premise of the cues-filtered-out perspective but instead highlights how visual anonymity obscures individuality of the self/others and causes people to orient themselves to a salient social category or group identity cues [49]. This explanation paradoxically suggests that the lack of interpersonal cues in CMC can lead subtle social context cues to take on a greater value and accentuate the salience of intergroup boundaries [67].

The SIDE model offers social influence explanations for uninhibited and antisocial CMC behavior. It challenges the reduced social cues perspective that solely ascribes technical properties of the medium to negative behavior and does not specify the precise conditions under which the behavior does and does not occur [5]. Unlike the traditional approach that links anonymity to online aggression [e.g., 68], this model posits that uncivil behaviors can also occur in non-anonymous CMC [69] and that anonymity allows people to follow a salient standard for a situationally "acceptable" act, even though it is negative and antisocial, as far as it meets the prevailing norm in the given context [70]. This is supported by evidence that aggressive language in user comments increased under an aggressive social norm for commenting, and this effect became stronger with online anonymity [71].

Given that social category cues (cf. individuating cues) are usually conveyed in the form of discrete information that is not sensitive to the bandwidth of a communication channel [5], the SIDE model argues that people, in anonymous $\mathrm{CMC}$, can identify others in terms of salient social dimensions. They can then decide their own behavior as well as evaluate others' behaviors based on the ways they support in-group norms [72]. All these processes involving social categorization and group influence can help hypothesize group-based bystander dynamics. For instance, individual bystanders may respond differently to online incivility incidents depending on whether the group membership of the perpetrator, target, and other bystanders does or does not overlap with their own identity. Regarding an incident perpetrated by an ingroup member targeting an out-group member, bystanders may consider it legitimate and justified situationally, especially when there is high hostility against the outgroup. Conversely, it is likely that bystanders may intervene against the in-group member's uncivil behavior if it is perceived as breaching their in-group norm (i.e., black sheep effects) [73]. In this case, in-group deviants may be assessed based on their personal faults rather than their group-based attributes. As such, bystanders may show in-group favoritism toward desirable deviants but ingroup derogation toward undesirable deviants, both of whom are, defined by the specific context.

The same in-group biases may also occur in the bystander-target relation. Given that belonging to a common group can facilitate prosocial behavior, especially when their in-group is under threat, bystanders may more willingly intervene for in-group (vs. out-group) targets [74]. In contrast, in-group derogation, or the black sheep effect, may occur when bystanders feel more desire to keep themselves from feeling shame and want to ensure a positive social identity for the whole group by separating the undesirable targets from good representatives [75]. If this is the case, the target's distress may be attributed to their own personality weakness or social ineptitude. This possibility may contribute to why racist messages towards an individual are sometimes evaluated as less harmful by in-group bystanders, rather than out-group bystanders [64].

Relations among bystanders matter as well. In fact, a potent factor driving intervention may lie in the degree of we-ness a bystander shares with fellow bystanders. Traditional bystander research showed that perceived similarity [76] or cohesiveness [77] within a bystander group could reverse the bystander apathy effect, revealing in-group biases around intervention. But according to a study on a Facebook group's intervention movement against online incivility [78], a shared social identity was not enough to elicit people's engagement. Instead, this study suggested that other group-level variables (e.g., group efficacy, group rule) should be considered when understanding collective action by online bystanders.

Taking these ideas together, the SIDE model's social influence explanation can be tailored for bystanders. That is, if a negative CMC behavior depends on the perceived group norm of that behavior, such normative influences can reach beyond perpetrators to include even those who observe the behavior. The model suggests that bystanders determine their behavior in response to group norms generated by in-group members' salient responses, since people primed with a certain behavior are more likely to comply to the prime-consistent norm [79]. One thing to note is that such a group norm has emergent and situational properties that arise from negotiated agreements among those involved in the particular context [80]. This implies that bystander intervention may not occur when no stable norms sanction such behavior. The current public commonly regards flaming or swearing as acceptable in online discussions because they are not considered a violation of negative expectancy [81].

As society has become tolerant of online incivility, bystander intervention may be more unlikely. Moreover, with increasingly intense social polarization, bystanders may consider any negative behavior directed against outgroups to be justifiable. If this is coupled with frequent encounters with in-group perpetrators, bystanders may become desensitized to and less inhibited by further hate speech [64]. This is exacerbated by not only descriptive norms ("what the majority does") but also injunctive norms ("what the majority approves"); that is, bystanders will more likely assimilate online incivility when it is perceived to be prevalent as well as socially approved. This is in line with earlier evidence that the Usenet group's 
tradition of verbal aggression was reinforced by new users mimicking "acceptable" behavior from existing users and socializing themselves to act similarly [24]. The same is also seen in today's adolescents who learn online hate to get approval from their peers [59].

\section{Social information processing theory}

The social information processing theory (SIP) [82] has been put forward to reveal the underestimated potentials of CMC. This theory criticizes the past approach of comparing CMC and FTF communication, which was confined to one-shot or an initial stage of interactions among unacquainted people. The theory argues that relational development in CMC should be examined based on ongoing interactions because it involves asynchronous interactions that require more time for the same amount of social information to accrue. If this temporal asymmetry is compensated, by allowing sufficient time and message exchanges, this theory believes people can develop relationships online that are as complete as those developed offline. Evidence supports this belief. For example, longitudinal CMC groups showed an increase in positive relational outcomes compared to FTF groups [83].

In this way, the SIP theory weakens the previous conclusion that CMC is inferior to FTF communication. However, the theory focuses primarily on socially oriented communication rather than antisocial communication. In one study that applied this theory to uninhibited negative verbal behavior (i.e., flaming), the expected moderating role of a time factor was not found [84]; that is, the amount of flaming within CMC was not different between timelimited and unlimited interactions, and the gap between CMC and FTF groups did not vary when the interaction was restricted. This finding suggests that the effects of ample time and messages might not be found in negative relational contexts of $\mathrm{CMC}$, which needs more research.

One of the basic beliefs underlying the SIP theory is that interpersonal relationships become less strained as they develop over time [85]. However, this may not be true for online incivility situations where one cannot easily alter an unfavorable impression formed at the initial stage of interaction. As the general aggression model argues, even a single exposure to a hostile message can elicit a relatively high level of negative arousal, which may not dissipate as easily as positive or neutral arousals. Triggering hostile cognitions can occur not only for targets but also bystanders [55]. If more time and more messages are allowed to make this kind of situation repeatedly and continuously occur, the rehearsal of aggressive cognition and affection may aggravate the problem. This may continue until negative arousal relaxes with accrued knowledge and reduced uncertainty about the perpetrator.

Meanwhile, although not specifically motivated by relational purposes, bystanders are likely to interact with fellow bystanders who may have common motivators- such as wanting to resolve the ambiguity of a situation or establish an appropriate context for their response of any kind. According to the SIP theory, if more time or message exchanges are allowed, bystanders may more likely engage in deliberate decision-making processes for intervention [86], based on accrued information from others.

But traditional bystander research suggests the opposite, clashing with the SIP theory's proposition. For example, Latane' and Nida [32] posited requisite communication conditions for the bystander apathy effect to occur. They found that the overall intervention rate was higher when the communication opportunity among bystanders was restricted, rather than when full communication was possible. This led to a counter-intuitive conclusion about the importance of communication possibilities among bystanders. For instance, more communication among bystanders could decrease their prosocial behavior, as opposed to the SIP theory's prediction. Due to such conflicting premises with the bystander theory and a paucity of relevant research, the SIP theory, at least for now, seems less than satisfactory as a general explanation framework for online bystander behavior.

\section{Hyperpersonal model of CMC}

The hyperpersonal model of CMC [87] aligns with the SIP theory since it also argues that CMC users make the most of cues available to form impressions and develop relationships. But this model goes further to explain how they can achieve such outcomes that surpass the level of affection and intimacy experienced by FTF interactants. Namely, hyperpersonal effects can be generated through a combination of four different, but related, elements of the communication process: selective self-presentation of the sender, over-attribution by the receiver, asynchronicity of the channel, and intensification of the feedback loop. These elements operate jointly to foster mediated social relationships that can exceed FTF relationships.

Evidence supports this view, showing that CMC users overcome limitations in the medium to accomplish a given task by compensating for the lack of nonverbal cues. Specifically, the users tend to employ a greater proportion of more direct strategies for uncertainty reduction (e.g., self-disclosure, in-depth question) and in turn gain greater confidence in predicting their partner's behavior than FTF interactants [88]. Furthermore, those who interact in longterm $\mathrm{CMC}$ report the most positive partner evaluations, compared to those in short-term CMC and those who switch from CMC to FTF communication [89], suggesting a maximized likelihood of hyperpersonal effects over time.

The hyperpersonal model argues that CMC allows people to exploit opportunities to "facilitate desired relationships" and "enhance relational outcomes" that exceed those in FTF communication, through the overaccommodation process that appears even when people interact with less desirable partners [90]. Some researchers explored the possibility of the hyperpersonal 
effects that might occur in negative CMC situations [e.g., 91]. They found that the anonymous and asynchronous nature of CMC might allow perpetrators (senders) to hide their identity and avoid immediate feedback. Targets (receivers) might then interpret the perpetrator's message in various ways, due to the absence of nonverbal cues, often overdramatizing the severity of the incident. As such, CMC settings can be more suited than FTF settings for perpetrators to achieve their aims to "facilitate desired relationships" (dominant-submissive relationship) and "enhance relational outcomes" (threat to the target).

Such negative hyperpersonal effects may underlie what is happening in the current online incivility phenomena, where CMC interactions promote hatred and harm that surpasses the level of those in FTF interactions. In effect, the hyperpersonal perspective may be more adequate for explaining perpetrator-target interactions, since it mainly focuses on the processes of message formulation and reception between the sender and receiver; it does not include the processes of evaluation or intervention by a third party, like bystanders. Nevertheless, one possible way to apply this model to bystander research is to situate bystanders also as receivers who read all messages generated during a developing incident.

The hyperpersonal model can allow scholars to entertain some possible scenarios for how online bystanders make causal inferences about the incident and decide their response. For instance, bystanders may regard the perpetrator's message as a kind of self-expression, such as intentionally unfavorable self-disclosure through destructive behavior [92]. If so, bystanders may exaggeratedly evaluate the perpetrator's antisocial traits and think it is more reasonable to support the target over the perpetrator [32]. The same negative over-attribution can also occur with respect to the target's message. If the target overshares personal information online-often indicative of increased vulnerability to cyberbullying [93] - bystanders may instead overestimate the target's undesirable traits and blame them.

Some possible explanations can also be derived from this model to elucidate differences between online and offline bystanders. If the anonymous and asynchronous channels of CMC serve to reduce evaluation apprehension that bystanders may have in FTF settings, they may be more likely to act for themselves online under less pressure from immediate social inhibitions [94]. Meanwhile, some scholars have extended the hyperpersonal model, suggesting that the sender's self-presentation might affect not only impression formation by the receiver but also selfperception by the sender themself (i.e., identity shift; [95]). From this, we can speculate why cyberbullying bystanders reported changes in their personality (e.g., reduced empathy) after remaining passive for a long time [96]. As such, a self-expression effect can occur for bystanders through their own behavior in response to online incivility.

\section{Conclusion}

\subsection{Summary}

This paper weighed the usefulness of the core theories of CMC for studying how bystanders are influenced by, or influence, today's online incivility problems. The social presence theory and reduced social cues perspective, enables us to predict that CMC may shift bystanders' attention away from the social context of an incident, instead making them more responsive to immediate verbal cues from an aggressive message. Such exposure may arouse hostile cognitions, by leading bystanders to behave in more impulsive and assertive manners, which suggests the emotional contagion effect. Regarding bystander intervention, competing possibilities can be entertained with the varying availability of cues. If a lack of social feedback online makes it difficult to construe an incident, such ambiguity may hamper intervention. But it is also hard to expect that intervention will be encouraged even if more social/visual cues are given, because an increase in the perceived social presence of others can exert inhibition effects on individual bystanders. The SIDE model can offer alternative accounts that better fit the classic notion of a bystander being sensitive to social contexts. This model can help existing bystander research move beyond the analyses of intraindividual/interpersonal processes. In doing so, it can further uncover how online incivility becomes tolerated, even normalized, by increased numbers of bystanders conforming to group norms. Applications of the SIP theory and hyperpersonal model of CMC, due to their concern with relatively long-term and senderreceiver-focused interactions, may not nicely fit research on short-term exposure experiences of online bystanders. There is a need for further research to enrich these two theories to encompass current uncivil behaviors online.

While assessing each theory's assumptions about the prosocial and antisocial potentials of $\mathrm{CMC}$, this paper also reached the conclusion that the original premises prompting these theories may need reexamination in light of new and ever-changing digital communication technologies. For example, the traditional cues-filtered-out perspective, which emerged based on text-only CMC settings, may not satisfactorily explain the dynamics in today's cue-rich online platforms. Another example is the SIDE model, which may also not fit every CMC context, particularly where short-lived and low-affinity interactions (or even one-off and instantaneous postings) occur and thus are not met with consequential social identification processes. In the same vein, explanations from the SIP theory and hyperpersonal model, which tend to conceive continuous and ongoing relationships, may be of limited value. These limitations call for more concerted scholarly inquiry into the reappraisal of CMC theories.

\subsection{Future research directions}


More fruitful discussions can take place by considering how future efforts should be directed to advance existing $\mathrm{CMC}$ theories for online bystander research. The current paper reveals that some theories-more precisely, the bounded set of assumptions within each-may conflict with each other. For example, regarding the effect of visual anonymity, the cues-filtered-out perspective predicts decreased group conformity among bystanders while the SIDE model predicts the opposite. Such incompatibility between the theories shows the complexity of the phenomenon but also opens new avenues for more robust theoretical deliberation. Future research should seek to explain how different $\mathrm{CMC}$ theories complement each other, given that the dynamics of online bystanders can be better understood with additional insights, which cannot otherwise be obtained from the individual theories. Inevitably, this paper must discuss how each theory can and should be extended to enhance its explanatory power on current online incivility phenomena. A straightforward but challenging way would be to revise each theory by adding new auxiliary hypotheses; however, this attempt may enlarge or diminish their relative scope.

The cues-filtered-out group of theories (social presence theory and reduced social cues perspective) needs to seek a possible explanation for why today's CMC, despite its greatly increased availability of nonverbal cues, still leads users to engage in self-focused, affectively negative, and impersonal communication. The scope of this explanation should be extended to include implications for message receivers (both targets and non-targets), instead of merely message senders, which have long been the focus of these early theories. In doing so, the theories should accommodate up-to-date evidence from contemporary multimodal and interactive technologies, such as video conferencing and augmented reality (AR). Those technologies can amplify the capabilities of online bystanders to perceive the virtual co-presence of others, be connected to each other, and adjust their (in)visibility.

For the SIDE model, which emphasizes group-level processes and intergroup relations, a question that has to be discussed in depth is how this model can apply into the context of large-scale online interactions, especially on open-access, crowd platforms that often serve as vigorous, violent places of public engagement (e.g., Twitter feeds, Reddit threads). In this communication setting, interindividual-based impressions (cf. inter-group-based impressions) may take precedence during the initial impression formation unless members of online groups develop cohesion. The model needs to explain the processes of how such platforms provoke SIDE dynamics among bystander groups, especially in response to online hate incidents involving social identity (e.g., race, gender).

The SIP theory and hyperpersonal model, despite their relatively limited usefulness, can be further developed by incorporating recent evidence of negative online behaviors. The advanced features of digital communication channels and emergence of new CMC language enable people to more rapidly and readily accrue impressions of and relations with others online. In response to these empirical challenges and technological developments, these two theories should attempt to explain the mechanisms of how such changes contribute to antisocial CMC patterns and amplify such negative effects to a level that exceeds those observed in FTF settings. This is a big challenge but also a significant opportunity, both in light of renewed tests of their validity and extensions of their explanatory power.

Along with the effort to improve individual theories, another challenge is how to deal with discussions comparing CMC and FTF communication-a common agenda of the theories - that are increasingly inconsequential today since digital technologies are thoroughly embedded in all aspects of everyday life. Given that CMC research, which initially held a dichotomous view (non-mediated versus mediated communication), is gradually having its boundaries blurred, it may be inevitable that these five theories need to reestablish their perspectives. It should be noted that, in the early literature on this comparative approach, discussions were mostly centered on whether and how (the then devalued) CMC parallels FTF communication in terms of prosocial and affiliative behavior. Attention can be, and should be, shifted to draw a parallel between the two in terms of antisocial behavior. This comparative approach can still be applied to future research on how and why today's CMC escalates risk and danger arising from online incivility situations that parallel, or even exceed, offline situations.

Extending concern with the FTF vs. CMC comparison, attention should be given to the possible interplay between online and offline interactions where bystanders witness the same uncivil incident in both contexts simultaneously. Evidence indicates that bystanders retained their roles across these contexts, but this was particularly true of those in an outsider role; conversely, other bystander roles (defender, reinforcer, assistant) were inconsistent between offline and online bullying situations [97]. That is, the overlap between offline and online bystander behavior might be accounted for mainly by inactive bystanders, rather than active bystanders. This gap can be explained by the particularities of $\mathrm{CMC}$ itself. But an important unknown to test is whether the psychological mechanisms underlying bystander behavior are fundamentally altered depending on the context. To determine this, future research should uncover bystanders' different decisionmaking processes in CMC and FTF situations, by exploring new factors affecting intervention, such as time constraints [98] or online/offline social bonds [99].

Beyond the theoretical discussions, future work should move to the next phase, where researchers would make more explicit connections between the theoretical frameworks and practices. As mentioned in the introduction, evidence from the real world suggests new possibilities for $\mathrm{CMC}$ theories to explain what is 
challenging today's online bystanders and why that matters. The resulting findings are significant for practitioners coping with online incivility, because they can offer practical tips for designing platforms in a way that does not interrupt bystander intervention. For example, digital platforms need more careful consideration when displaying the kinds and amounts of "cues" generated by their systems and users, in order to prevent the bystander apathy effect or induce the non-negative bystander effect (i.e., the role of fellow bystanders to influence a bystander to become prosocial; [100]). The advancement of CMC theories, suggested in this paper, can inform a variety of influential moderators of these effects, which should be investigated to help optimize the chances that platform policies and interfaces effectively mitigate online incivility.

\section{References}

[1] S. R. Hiltz and M. Turoff, The network nation: Human communication via computer, MIT Press, 1978.

[2] R. Kling, "Social analyses of computing: Theoretical perspectives in recent empirical research", Computing Surveys, 12, 1980, pp. 61-110.

[3] R. E. Rice and G. Love, "Electronic emotion: Socioemotional content in a computer-mediated communication network", Communication Research, 14, 1987, pp. 85-108.

[4] A. Joinson, "Causes and implications of disinhibited behavior on the Internet", in J. Gackenbach (Ed.), Psychology and the Internet: Intrapersonal, interpersonal, and transpersonal implications, Academic Press, 1998, pp. 43-60.

[5] M. Lea, T. O'Shea, P. Fung, and R. Spears, "'Flaming' in computermediated communication: Observations, explanations, implications", in M. Lea (Ed.), Contexts of computer-mediated communication, HarvesterWheatsheaf, 1992, pp. 89-112.

[6] F. Sabatini and T. Reggiani, "Locking horns: Online incivility is seen as the new normal, and it inhibits social trust", United States Politics and Policy, 2019, https://blogs.lse.ac.uk/businessreview/2019/03/26/lockinghorns-online-incivility-is-seen-as-the-new-normal-and-it-inhibits-socialtrust/

[7] A. Antoci, L. Bonelli, F. Paglieri, T. G. Reggiani, and F. Sabatini, "Civility and trust in social media", IZA Discussion, 2018, https://newsroom.iza.org/en/archive/research/civility-and-trust-in-socialmedia/

[8] D. A. Snow, L. A. Zurcher, and R. Peters, "Victory celebrations as theater: A dramaturgical approach to crowd behavior", Symbolic Interaction, 4, 1981, pp. 21-42.

[9] Pew Research Center, "Key takeaways on how Americans view - and experience - online harassment", 2017, www.pewresearch.org/facttank/2017/07/11/key-takeaways-online-harassment/

[10] R. Terry, "How to be an active bystander when you see casual racism", The New York Times, 2020, www.nytimes.com/2020/10/29/smarterliving/how-to-be-an-active-bystander-when-you-see-casual-racism.htm

[11] C. Straumsheim, "Online classmates or bystanders?", Inside Higher ED, 2015, www.insidehighered.com/news/2015/07/01/study-examinesbystander-behavior-cyberbullying-cases

[12] S. Jones, "What is the real-world impact of online hate speech on young people?", internetmatters.org, n.d.

www.internetmatters.org/hub/question/what-is-the-real-world-impact-ofonline-hate-speech-on-young-people/

[13] C. Haberman, "What the Kitty Genovese Killing can teach today's digital bystanders", The New York Times, 2017, www.nytimes.com/2017/06/04/us/retro-report-bystander-effect.html

[14] S. Scheff, "Shame nation: The rise of incivility in America", Huffpost, 2017, www.huffpost.com/entry/shame-nation-the-rise-of-incivility-inamerica b 591357d3e4b0e070cad70b2f

[15] M. Brauer and P. Chekroun, "The relationship between perceived violation of social norms and social control: Situational factors influencing the reaction to deviance", Journal of Applied Social Psychology, 35, 2005, pp. 1519-1539.

[16] J. Short, E. Williams, and B. Christie, The social psychology of telecommunications, Wiley, 1976

[17] M. Argyle and J. Dean, "Eye-contact, distance and affiliation", Sociometry, 28, 1965, pp. 289-304.
[18] M. Wiener and A. Mehrabian, Language within language: Immediacy, a channel in verbal communication, Ardent Media, 1968.

19] C. N. Gunawardena and F. J. Zittle, "Social presence as a predictor of satisfaction within a computer-mediated conferencing environment", American Journal of Distance Education, 11, 1997, pp. 8-26.

20] E. Williams, "Experimental comparisons of face-to-face and mediated communication: A review", Psychological Bulletin, 84, 1977, pp. $963-$ 976.

21] S.A. Shamp, "Mechanomorphism in perception of computer communication partners", Computers in Human Behavior, 7, 1991, pp. 147-161

$22]$ L. Sproull and S. Kiesler, "Reducing social context cues: Electronic mail in organizational communication", Management Science, 32, 1986, pp. $1492-1512$

23] M. Smilowitz, D. C. Compton, and L. Flint, "The effects of computer mediated communication on an individual's judgement: A study based on the methods of Asch's social influence experiment", Computers in Human Behavior, 4, 1988, pp. 311-321.

[24] M-S. Kim and N. S. Raja, "Verbal aggression and self-disclosure on computer bulletin boards", Paper presented at the Annual Meeting of the International Communication Association, Chicago, IL, 1990.

[25] W. Gao, Z. Liu, and J. Li, "How does social presence influence SNS addiction? A belongingness theory perspective", Computers in Human Behavior, 77, 2017, pp. 347-355.

[26] J. Suler, "The online disinhibition effect", Cyberpsychology \& Behavior, 7, 2004, pp. 321-326.

[27] L. Mark and K. T. Ratliffe, "Cyber worlds: New playgrounds for bullying", Computers in the Schools, 28, 2011, pp. 92-116.

[28] R. Slonje and P. K. Smith, "Cyberbullying: Another main type of bullying?", Scandinavian Journal of Psychology, 49, 2008, pp. 147-154.

[29] P. K. Smith, J. Mahdavi, M. Carvalho, S. Fisher, S. Russell, and N. Tippet, "Cyberbullying: Its nature and impact in secondary school pupils", Journal of Child Psychology Psychiatry, 49, 2008, pp. 376-385.

[30] B. Latané and J. M. Darley, "Group inhibition of bystander intervention in emergencies", Journal of Personality and Social Psychology, 10, 1968, pp. $215-221$

[31] B. Latané and J. M. Darley, Help in a crisis: Bystander response to an emergency, General Learning Press, 1976.

[32] B. Latané and S. Nida, "Ten years of research on group size and helping", Psychological Bulletin, 89, 1981, pp. 308-324.

[33] P. M. Markey, "Bystander intervention in computer-mediated communication", Computers in Human Behavior, 16, 2000, pp. 183-188.

[34] L. Leonhard, C. Rueß, M. Obermaier, and C. Reinemann, "Perceiving threat and feeling responsible: How severity of hate speech, number of bystanders, and prior reactions of others affect bystanders' intention to counterargue against hate speech on Facebook", SCM Studies in Communication and Media, 7, 2018, pp. 555-579.

[35] B. Latané, "The psychology of social impact", American Psychologist, 36, 1981, pp. 343-356.

[36] M. W. Baldwin and J. G. Holmes, "Salient private audiences and awareness of the self", Journal of Personality and Social Psychology, 52, 1987, pp. 1087-1098.

[37] T. B. Sheridan, "Musings on telepresence and virtual presence", Presence: Teleoperators and Virtual Environments, 1, 1992, pp. 120-126.

[38] E. Goffman, Behavior in public places, The Free Press, 1963.

[39] N. Lapidot-Lefler and A. Barak, "Effects of anonymity, invisibility, and lack of eye-contact on toxic online disinhibition", Computers in Human Behavior, 28, 2012, pp. 434-443.

[40] F. Biocca, C. Harms, and J. K. Burgoon, "Toward a more robust theory and measure of social presence: Review and suggested criteria", Presence: Teleoperators \& Virtual Environments, 12, 2003, pp. 456-480.

[41] C. Heeter, "Being there: The subjective experience of presence", Presence: Teleoperators \& Virtual Environments, 1, 1992, pp. 262-271.

[42] K. Nowak, "Defining and differentiating copresence, social presence and presence as transportation", Paper presented at the Fourth International Workshop on Presence, Philadelphia, PA, 2001.

[43] T. L. Griffith, M. A. Fuller, and G. B. Northcraft, "Facilitator influence in group support systems: Intended and unintended effects", Information Systems Research, 9, 1998, pp. 20-36.

[44] J. Siegel, V. Dubrovsky, S. Kiesler, and T. W. McGuire, "Group processes in computer-mediated communication", Organizational Behavior and Human Decision Processes, 37, 1986, pp. 157-187.

[45] V. J. Dubrovsky, S. Kiesler, and B. N. Sethna, "The equalization phenomenon: Status effects in computer-mediated and face-to-face decision-making groups", Human-computer Interaction, 6, 1991, pp. 119146.

[46] S. Kiesler, J. Siegel, and T. W. McGuire, "Social psychological aspects of computer-mediated communication”, American Psychologist, 39, 1984, pp. 1123-1134

[47] L. Festinger, A. Pepitone, and T. Newcomb, "Some consequences of deindividuation in a group", The Journal of Abnormal and Social Psychology, 47, 1952, pp. 382-389. 
[48] P. A. Thompsen, "What's fueling the flames in cyberspace: A social influence model", in L. Strate, R. Jacobson, and S. Gibson (Eds.), Communication and cyberspace: Social interaction in an electronic environment, Hampton, 1996, pp. 297-315.

[49] T. Postmes, R. Spears, and M. Lea, "Breaching or building social boundaries? SIDE-effects of computer-mediated communication", Communication Research, 25, 1998, pp. 689-715.

[50] N. S. Baron, "Computer mediated communication as a force in language change", Visible Language, 18, 1984, pp. 118-141.

[51] J. Stromer-Galley, "New voices in the political sphere: A comparative analysis of interpersonal and online political talk", Javnost-The Public, 9 , 2002 , pp. 23-42.

[52] K. Coe, K. Kenski, and S. A. Rains, "Online and uncivil? Patterns and determinants of incivility in newspaper website comments", Journal of Communication, 64, 2014, pp. 658-679.

[53] C. A. Anderson and N. L. Carnagey, "Violent evil and the general aggression model", in A. Miller (Ed.), The social psychology of good and evil, Guilford, 2004, pp. 168-192.

[54] H. Hwang, Z. Pan, and Y. Sun, "Influence of hostile media perception on willingness to engage in discursive activities: An examination of mediating role in media indignation", Media Psychology, 11, 2008, pp. 76-97.

[55] L. Rösner, S. Winter, and N. C. Krämer, "Dangerous minds? Effects of uncivil online comments on aggressive cognitions, emotions, and behavior", Computers in Human Behavior, 58, 2016, pp. 461-470.

[56] P. Borah, "Does it matter where you read the news story? Interaction of incivility and news frames in the political blogosphere", Communication Research, 41, 2014, pp. 809-827.

[57] D. J. Brooks and J. G. Geer, "Beyond negativity: The effects of incivility on the electorate", American Journal of Political Science, 51, 2007, pp. 1 16

[58] G. M. Chen and S. Lu, "Online political discourse: Exploring differences in effects of civil and uncivil disagreement in news website comments", Journal of Broadcasting \& Electronic Media, 61, 2017, pp. 108-125.

[59] S. Wachs, M. F. Wright, R. Sittichai, R. Singh, R. Biswal, E. M. Kim ... V. Daskalou, "Associations between witnessing and perpetrating online hate in eight countries: The buffering effects of problem-focused coping", International Journal of Environmental Research and Public Health, 16, 2019 , pp. 1-13.

[60] E. Hatfield, J. T. Cacioppo, and R. L. Rapson, Emotional contagion, Cambridge University Press, 1994.

[61] A. D. Kramer, J. E. Guillory, and J. T. Hancock, "Experimental evidence of massive-scale emotional contagion through social networks", Proceedings of the National Academy of Sciences, 111, 2014, pp. 87888790.

[62] R. D. Clark and L. E. Word, "Why don't bystanders help? Because of ambiguity?", Journal of Personality and Social Psychology, 24, 1972, pp. 392-400.

[63] L. Z. Solomon, H. Solomon, and R. Stone, "Helping as a function of number of bystanders and ambiguity of emergency", Personality and Social Psychology Bulletin, 4, 1978, pp. 318-321.

[64] L. Leets and H. Giles, "Words as weapons - when do they wound? Investigations of harmful speech", Human Communication Research, 24 1997, pp. 260-301

[65] S. M. Garcia, K. Weaver, G. B. Moskowitz, and J. M. Darley, "Crowded minds: The implicit bystander effect", Journal of Personality and Social Psychology, 83, 2002, pp. 843-853.

[66] S. D. Reicher, R. Spears, and T. Postmes, "A social identity model of deindividuation phenomena”, European Review of Social Psychology, 6, 1995, pp. 161-198.

[67] R. Spears, T. Postmes, M. Lea, and S. E. Watt, "A SIDE view of social influence", in J. P. Forgar and K. D. Williams (Eds.), Social influence: Direct and indirect processes. The Sydney symposium on social psychology series (Vol. 3), Cambridge University Press, 2001, pp. 331350.

[68] R. Kling, Y. C. Lee, A. Teich, and M. S. Frankel, “Assessing anonymous communication on the Internet: Policy deliberations", The Information Society, 15, 1999, pp. 79-90.

[69] Pew Research Center, "The tone of life on social networking sites," 2012, www.issuelab.org/resources/12498/12498.pdf

[70] R. Spears and M. Lea, "Panacea or panopticon? The hidden power in computer-mediated communication", Communication Research, 21, 1994, pp. 427-459.

[71] L. Rösner and N. C. Krämer, "Verbal venting in the social web: Effects of anonymity and group norms on aggressive language use in online comments", Social Media+ Society, 2, 2016, pp. 1-13.

[72] J. C. Turner, M. A. Hogg, P. J. Oakes, S. D. Reicher, and M. C. Wetherell, Rediscovering the social group: A self-categorization theory, Basil Blackwell, 1987.

[73] J. M. Marques, "The black sheep effect: Outgroup homogeneity in social comparison settings", in D. Abrams and M. Hogg (Eds.), Social identity theory: Constructive and critical advances, Harvester Wheatsheaf, 1990, pp. 131-151

[74] M. Levine and S. Crowther, "The responsive bystander: How social group membership and group size can encourage as well as inhibit bystander intervention", Journal of Personality and Social Psychology, 95, 2008, pp. $1429-1439$

[75] H. Tajfel, "Social psychology of intergroup relations", Annual Review of Psychology, 33, 1982, pp. 1-39.

[76] M. Levine, C. Cassidy, G. Brazier, and S. Reicher, "Self-categorization and bystander non-intervention: Two experimental studies", Journal of Applied Social Psychology, 32, 2002, pp. 1452-1463.

[77] G. K. Rutkowski, C. L. Gruder, and D. Romer, "Group cohesiveness, social norms, and bystander intervention", Journal of Personality and Social Psychology, 44, 1983, pp. 545-552.

[78] M. Ziegele, T. K. Naab, and P. Jost, "Lonely together? Identifying the determinants of collective corrective action against uncivi comments", New Media \& Society, 22, 2020, pp. 731-751.

[79] T. Postmes, R. Spears, K. Sakhel, and D. de Groot, "Social influence in computer-mediated communication: The effects of anonymity on group behavior", Personality and Social Psychology Bulletin, 27, 2001, pp. 1243-1254

[80] P. B. O'sullivan and A. J. Flanagin, "Reconceptualizing 'flaming' and other problematic messages", New Media \& Society, 5, 2003, pp. 69-94.

[81] J. K. Burgoon, "Interpersonal expectations, expectancy violations, and emotional communication", Journal of Language and Social Psychology, 12, 1993, pp. 30-48.

[82] J. B. Walther, "Interpersonal effects in computer-mediated interaction: A relational perspective", Communication Research, 19, 1992, pp. 52-90.

[83] J. B. Walther and J. K. Burgoon, "Relational communication in computermediated interaction", Human Communication Research, 19, 1992, pp. $50-88$

[84] J. B. Walther, J. F. Anderson, and D. W. Park, "Interpersonal effects in computer-mediated interaction: A meta-analysis of social and antisocia communication", Communication Research, 21, 1994, pp. 460-487.

[85] M. L. Knapp, "Interpersonal communication and human relationships", Journal of Clinical Psychology, 6, 1984, pp. 47-58.

[86] B. Latané and J. M. Darley, The unresponsive bystander: Why doesn't he help?, Appleton-Century-Crofts, 1970.

[87] J. B. Walther, "Computer-mediated communication: Impersonal, interpersonal, and hyperpersonal interaction", Communication Research, 23, 1996, pp. 3-43.

[88] L. C. Tidwell and J. B. Walther, "Computer-mediated communication effects on disclosure, impressions, and interpersonal evaluations: Getting to know one another a bit at a time", Human Communication Research, 28,2002 , pp. $317-348$.

[89] A. Ramirez, Jr. and Z. Wang, "When online meets offline: An expectancy violation theory perspective on modality switching", Journal of Communication, 58, 2008, pp. 20-39.

[90] J. B. Walther, "Selective self-presentation in computer-mediated communication: Hyperpersonal dimensions of technology, language, and cognition", Computers in Human Behavior, 23, 2007, pp. 2538-2557.

[91] L. C. Farrell, "The role of cyber and face-to-face verbal bullying on adolescent victims", Journal of the Communication, Speech \& Theatre Association of North Dakota, 25, 2012, pp. 25-36.

[92] M. Alonzo and M. Aiken, "Flaming in electronic communication", Decision Support Systems, 36, 2004, pp. 205-213.

[93] H. L. Schacter, S. Greenberg, and J. Juvonen, "Who's to blame?: The effects of victim disclosure on bystander reactions to cyberbullying", Computers in Human Behavior, 57, 2016, pp. 115-121.

[94] S. H. Schwartz and A. Gottlieb, "Bystander anonymity and reactions to emergencies", Journal of Personality and Social Psychology, 39, 1980, pp. $418-430$

[95] A. L. Gonzales and J. T. Hancock, "Identity shift in computer-mediated environments" Media Psychology, 11, 2008, pp. 167-185.

[96] S. Pabian, H. Vandebosch, K. Poels, K. Van Cleemput, and S. Bastiaensens, "Exposure to cyberbullying as a bystander: An investigation of desensitization effects among early adolescents", Computers in Human Behavior, 62, 2016, pp. 480-487.

[97] R. Quirk and M. Campbell, "On standby? A comparison of online and offline witnesses to bullying and their bystander behaviour", Educational Psychology, 35, 2015, pp. 430-448.

[98] M. Brewster and J. M. Tucker, "Understanding Bystander Behavior: The Influence of and Interaction Between Bystander Characteristics an Situational Factors", Victims \& Offenders, 11, 2015, pp. 455-481.

[99] M. Costello, J. Hawdon, and A. Cross, "Virtually standing up or standing by? Correlates of enacting social control online", International Journal of Criminology and Sociology, 6, 2016, pp. 16-28.

[100] P. Fischer, J. I. Krueger, T. Greitemeyer, C. Vogrincic, A. Kastenmüller, D. Frey, ... \& M. Kainbacher, "The bystander-effect: a meta-analytic review on bystander intervention in dangerous and non-dangerous emergencies", Psychological bulletin, 137, 2011, pp. 517-537. 